\title{
EL TIEMPO BARROCO EN FRANCISCO REBOLLEDO Y ALEJO CARPENTIER \\ Andreas Kurz*
}

Francisco Rebolledo publicó su primera novela Rasero a finales de 1993. La historia del español Fausto Rasero quien, en la gloriosa Francia del siglo XVIII, es elegido como amigo por Denis Diderot, Voltaire, Antoine Lavoisier, Madame de Pompadour y hasta por Mozart, alcanzó -a pesar de sus 633 páginas- un éxito respetable en las librerías, fue acogida con elogios por la crítica y se tradujo al inglés y al francés. Quizás precisamente por tratarse de un éxito 'comercial', la crítica académica se ocupó relativamente poco del texto. Sus propuestas narrativas muy pronto fueron ofuscadas por el impacto que Jorge Volpi produjo con En busca de Klingsor, sobre todo en la

* Departamento Académico de Estudios Generales, ITAM. crítica española y francesa. No cabe duda, sin embargo, de que Rasero es una de las novelas mexicanas más logradas y, a la vez, más desconcertantes, publicadas en los últimos 15 años. El texto incluye rasgos de novela histórica y científica, de cuento erótico, así como de la ciencia ficción y sobre todo es un juego laberíntico con el tiempo, que es tanto historia como tiempo vivido. Fausto Rasero ve el futuro en el momento del orgasmo que, gracias a la irresistible atracción erótica de su calva y de sus ojos brillantes, alcanza a menudo. En este sentido Rasero es un verdadero Fausto goethiano, aunque sin haber pactado con el demonio. Es un ser privilegiado que goza y sufre por sus conocimientos que lo destacan frente a sus contemporáneos, aunque éstos se llamen Voltaire o Diderot. Él sabe 
más y tiene que darse cuenta, dolorosamente, de que todos los intentos geniales de la ilustración francesa, del siglo de las luces, para educar el mundo y crear un hombre capaz de disfrutar su condición humana sin prejuicios y supersticiones, serán en vano. Fausto Rasero renuncia a la escritura. Lo que él podría escribir ya existe: El Apocalipsis de San Juan. Además, conociendo el futuro, se percata prematuramente del axioma frustrante de la modernidad: la vacuidad del signo. Lo que Kafka diseña en sus narraciones desesperantes que 'sólo' trazan signos narrativos sin contenido, en plena conciencia de la indescifrabilidad y lo obsoleto del libro de la naturaleza, ${ }^{1}$ el español Rasero lo vive en el siglo XVIII, precisamente en medio de la época histórica que genera la modernidad. De hecho, Rasero puede insinuar una frustración más allá del signo vacío. Como ya conoce el futuro, los intentos de Voltaire, entre muchos otros, de construir el mundo y la existencia mediante el acto de trazar signos sobre el papel, le tienen que parecer inútiles. La esperanza de Kafka, o de escritores más recientes como el austriaco Peter Handke, de que el signo pueda ser capaz de construir autóno-

${ }^{1}$ El libro de la naturaleza, es decir, la representación del mundo entero en un texto, fue escrito por Dios, borrado por la ilustración y resucitado por Foucault y Derrida. mamente su propio significado, de procesarlo, se diluye. En un cuento de 1975, Handke todavía puede escribir: "En la arena a sus pies vio tres cosas: una hoja de un castaño; un trozo de un espejo de bolsillo; un pasador para la trenza de una niña. Todo el tiempo habían estado ahí, pero de repente se juntaron estos objetos para formar cosas prodigiosas. - ¿Quién dice que el mundo ya se ha descubierto?'."2 Podemos contestar la pregunta del escritor austriaco: Fausto Rasero lo dice. Kafka, a quien Handke alude explícitamente en este texto -su personaje se llama Gregor Keuschnig- no comparte el optimismo de su sucesor. Acordémonos del final de El proceso. Cuando la sentencia de muerte se ejecuta, Josef $\mathrm{K}$. ve que se abre la ventana de una casa cercana, y se asoma un ser humano extendiendo sus brazos hacia él. “¿Quién era? ¿Un amigo? ¿Un hombre bueno? ¿Uno compasivo? ¿Uno que quiso ayudar? ¿Era un individuo? ¿Eran todos? ¿Todavía había ayuda? ¿Existían objeciones que se habían olvidado? La lógica es imperturbable, pero no resiste a un hombre quien quiere vivir."3 Puede que la lógica no se resista a

2 Peter Handke, Die Stunde der wahren Empfindung, 1978, Frankfurt, Suhrkamp, p. 81. La traducción es mía.

${ }^{3}$ Franz Kafka, Der Prozeß, 1979, Frankfurt, Fischer, p. 194. La traducción es mía. 
la esperanza, pero finalmente acaba con ella: "Pero las manos de uno de los señores apretaron la garganta de K., mientras que el otro le clavó el cuchillo muy profundo en el corazón y dio dos vueltas ahí." ${ }^{\prime 4}$ Rasero repite el gesto de K. que muere 'como un perro'. Conoce a la maravillosa mexicana Mariana y se enamora profundamente de ella. Por primera vez desaparecen sus visiones nefastas en el momento del orgasmo, el signo se puede llenar de un significado y Rasero goza del momento, disfruta la relación con Mariana (no sólo la física) y olvida su saber, es decir, puede renunciar a la razón que, en última instancia -y Rasero lo sabelleva al sinsentido de la modernidad. Pero la lógica kafkiana se impone: Mariana desaparece. Es un ser que pertenece a un tiempo fuera del alcance de Rasero, quizás fuera del alcance de la historia humana. La joven mexicana deja, junto a una fotografía que no existía en el siglo XVIII, un soneto en el cual anuncia una reunión con Rasero: "Vuelvo, Fausto, a mi tierra americana / (pero cuando cuenten, dice mi instinto, / de haberla descubierto el siglo quinto); / allá y entonces te espera tu Mariana." ${ }^{5}$ La reunión sólo será posible en la muerte de Fausto Rasero, cuando

${ }^{4}$ Ibidem.

${ }^{5}$ Francisco Rebolledo, Rasero, 1993, México, Joaquín Mortiz, p. 464. -ojalá- los signos recobren su significado. Esta vaga esperanza deja Mariana. Es el gesto del desconocido que abre sus brazos en la novela de Kafka. El querer vivir en medio de la desesperación más desgarradora. Es el gesto también de Sísifo, el de Albert Camus, quien, a pesar de todo, no se suicida. Es, finalmente, el mecanismo del amor pasional, descrito magistralmente por Denis de Rougemont en Amor y Occidente, cuya meta es la pasión misma, alcanzable sólo en la muerte

En realidad el texto de Rebolledo genera dos esperanzas: América y el tiempo. La sinrazón mexicana, el país surrealista por excelencia, según Breton y Dalí, irrumpe en el mundo cerebral del siglo XVIII francés y en la vida razonada de Rasero. El español conoce la ciudad de París, que habitó durante 20 años, a través de los ojos de la mexicana, quien acaba de verla por primera vez: “ ¡Si fue ella quien le hizo conocer París! Llevaba más de veinte años en esta ciudad, convencido de que era el mejor lugar del mundo para vivir y, en apenas dos meses descubre que París le era tan desconocido como pueden serlo esas remotas tierras de las que habla Mariana con tanto entusiasmo." Rasero conoce la abstracción, los libros, pero no las cosas. Mariana

${ }^{6}$ Ibid., p. 317. 
le enseña que hasta en los objetos más aborrecibles hay un mundo que se puede descubrir. Un recolector de estiércol le comunica que la mierda refleja el estatus social de sus productores: "Vale mucho más el excremento de un primer piso que el de un cuarto, por ejemplo. Es de gente mejor alimentada, sus desechos están más cargados, rinden mucho mejor en el campo." As Así como Mariana sólo puede existir gracias a la curiosidad humana que impulsó a Cristóbal Colón, el mundo cotidiano sólo se 'descubre' por la curiosidad. Los signos están vacíos, pero no -y aquí se asoma Gadamer, consciente o inconscientemente- el uso que se da a los objetos. Mariana opera un cambio decisivo en Fausto Rasero. Inclusive después de su desaparición modela la existencia del español. Fausto retoma una de sus viejas pasiones académicas: la química. En el laboratorio, que Mariana le había regalado, Lavoisier encuentra la base para su logro más importante: desacreditar de una vez por todas la teoría del flogisto. Rasero, por su parte, olvida su desgraciada existencia en la química, la ciencia más 'concreta' imaginable que sólo se ocupa de la reacción de las substancias, de su uso y de las posibles transformaciones del uso. México,

\footnotetext{
${ }^{7}$ Ibid., p. 336.
}

por ende, y América Latina por extensión, se presenta como el oxígeno -(re)descubierto por Lavoisier- que Europa necesita para respirar. En este aspecto se concreta la afinidad de la novela con los diversos programas culturales del cubano-francés Alejo Carpentier. Lo real maravilloso, la escritura barroca latinoamericana, la novela épica giran en torno a las siempre complicadas relaciones culturales y sociales entre Europa e Hispanoamérica, pero también se preocupan por la posibilidad de narrar un mundo.

Carpentier, quien formuló sus posiciones al respecto sobre todo a raíz de su recepción, muy influida por los acontecimientos históricos, del ensayo monumental de Oswald Spengler La decadencia de occidente, interpreta la cultura hispanoamericana como una infusión de vida que reclama urgentemente el viejo continente. Ya en 1928 el autor de Los pasos perdidos escribió en "La consagración de nuestros ritmos" acerca del éxito de la música cubana en los círculos intelectuales y populares de París:

Por muy humilde que sea el núcleo de un elemento folklórico, ese elemento, una vez cristalizado, se muestra siempre dotado de una lozanía y un frescor incomparables. Y mientras más vieja sea una civilización, más deberá recurrir a 
esos factores de juventud y carácter, que vendrán a animar sus miembros cansados, su espíritu siempre acechado por la 'barbarie intelectual' de que hablaba Paul Valéry [...] La música cubana es esencia de ritmo, de sol, de vida. ¿Qué pueden temer de tan preciada aportación las viejas civilizaciones de Europa? ${ }^{8}$

Carpentier se dará cuenta de la ingenuidad de sus posiciones y más tarde las reformulará y aplicará, a partir de El reino de este mundo, como sincretismo literario y cultural entre los dos continentes. El tema y los lugares sí son americanos en su novela de 1949, mas la reflexión sobre ellos es europea. Repite esta constelación en Los pasos perdidos, y la invierte en El siglo de las luces: los lugares son europeos, su penetración intelectual es latinoamericana.

En Rasero, Francisco Rebolledo amplía este concepto. En su mayoría, los lugares y personajes son europeos, la reflexión sobre ellos es occidental y estrictamente racional, pero la esperanza ontológica que genera tiene su origen en América Latina. Sin embargo, la segunda esperanza, la temporal, propuesta por el texto del mexicano, me parece más decisiva y menos ingenua. Además,

${ }^{8}$ Alejo Carpentier, "La consagración de nuestros ritmos", Crónicas 1. Arte, literatura, politica, Obras completas 8, 1985, México, Siglo XXI, p. 211-6, aquí p. 215. el manejo del tiempo es definitivamente una obsesión que comparten los dos autores. Carpentier expresa su fascinación por el tiempo tanto en novelas como Los pasos perdidos o El siglo de las luces, como en sus pocas narraciones, en primer lugar en "Semejante a la noche" y, de manera prototípica, en "Viaje a la semilla". Este relato comienza con unos obreros que derrumban el palacio, probablemente cerca de Madrid, de Don Mariscal, recién fallecido. Cayendo la noche los trabajadores se van con el propósito de terminar la obra el siguiente día. En los capítulos que siguen, del II al XII, Carpentier narra al revés la vida de Don Mariscal. Éste abre los ojos y 'despierta' de la muerte, la casa se llena poco a poco con ruidos, con voces que aparecen y desaparecen, el dueño rejuvenece, se transforma en niño y, finalmente, Don Mariscal cierra los ojos de nuevo y "penetró en un cuerpo caliente, húmedo, lleno de tinieblas, que moría", el cuerpo de su madre muerta durante el parto. ${ }^{9}$ Desaparece también la casa hacia los tiempos antes de su construcción. Al día siguiente regresan los obreros y 'encontraron el trabajo acabado'. ${ }^{10}$

${ }^{9}$ Alejo Carpentier, "Viaje a la semilla", Guerra del tiempo, El acoso y otros relatos, Obras completas 3, 1985, México, Siglo XXI, p. 13-29, aquí p. 27.

${ }^{10}$ Ibid., p. 28. 
NOTAS

No se trata de un tiempo cíclico, sino el cuento refleja la estructura de una espiral. Para los obreros el tiempo transcurre como siempre, pero tanto el tiempo narrativo, como el tiempo narrado se rigen por un sol que viaja de occidente a oriente. ${ }^{11}$ Este 'viaje a la semilla', sin embargo, tiene consecuencias palpables en el tiempo de los obreros: Su trabajo ya está hecho. El círculo no se cierra sino que hay un avance temporal. Carpentier, en muchas ocasiones, expresa la idea de que bajo esta forma se esconde el origen de la vida. Sobre todo su fascinación por el barroco surge a raíz de tal fijación. En El siglo de las luces, Esteban contempla un caracol y llega a conclusiones realmente metafísicas:

Meditaba acerca de la poma del erizo, la hélice del muergo, las estrías de la venera jacobita, asombrándose ante aquella Ciencia de las Formas desplegada durante tantísimo tiempo frente a una humanidad aún sin ojos para pensarla. ¿Qué habrá en torno mío que esté ya definido, inscrito, presente, y que aún no pueda entender? ¿Qué signo, qué mensaje, qué advertencia, en los rizos de la achicoria, el alfabeto

${ }^{11}$ Carpentier concluye el cuento de la siguiente manera: "el sol viajaba de oriente a occidente, y las horas que crecen a la derecha de los relojes deben alargarse por la pereza, ya que son las que más seguramente llevan a la muerte", p. 28. de los musgos, la geometría de la pomarrosa? Mirar un caracol. Uno solo. Tedéum. ${ }^{12}$

Los signos están vacíos y la escritura ya no puede llenarlos con significados. Pero existen las formas y los usos que sólo se representan a sí mismos. La escritura, el lenguaje en general, nos acercan a estas representaciones, pero nunca pueden construirlas ellos mismos. Un caracol, para Carpentier, representa por su forma el transcurso del tiempo en espiral que regresa a sí mismo, después de haber producido un objeto barroco, es decir, sumamente complicado y no captable por medio de una razón rectilínea, del tipo deductivo o inductivo. Sólo se necesita un pequeño paso más para simbolizar una vida individual, o la vida de la humanidad, en forma de espiral que regresa a su punto de origen. Obviamente el lenguaje me traiciona aquí, ya que no se trata de representaciones, ni de simbolizaciones, sino de puras presencias. En la novela de Rebolledo, estas presencias se captan, ya no

12 Alejo Carpentier, El siglo de las luces, Obras completas 5, 1986, México, Siglo XXI, p. $252 \mathrm{~s}$. El cubano elaboró su teoría barroca, sus ideas de una repetición cíclica de ciertas constantes artísticas y vitales, con base en sus lecturas de los historiadores de arte Heinrich Wölfflin y Wilhelm Worringer, suizo el primero, alemán el segundo, resumidas y sintetizadas por el catalán Eugenio d'Ors. 
con palabras, sino con estructuras y juegos temporales. Después de perder a Mariana, Rasero se contempla a sí mismo en el futuro, más joven y hasta con pelo, pero indudablemente él. En su visión, el Rasero del futuro hojea una edición especial del Apocalipsis de San Juan que el Rasero del siglo XVIII hizo preparar. Rasero regresa a la muerte, que no es nacimiento, pero sí punto de partida para otro movimiento en espiral, sólo un poco más adelantado. El español explica así el sinsentido de la historia: el movimiento del caracol implica que ciertas fases tienen que repetirse. Las guerras del siglo XVIII tienen que regresar en el siglo XX, pero desgraciadamente más adelantadas, con métodos para matar mucho más sofisticados. La protesta que, por lo menos en un comienzo, implicaba la revolución francesa de 1789, se reanudará en 1968 , pero a nivel global y más fundamentada. En el capítulo V de Rasero, dedicado precisamente a Mariana, Rebolledo construye un punto cero en el tiempo que podría ser el inicio de otro movimiento en espiral. El capítulo comienza en diciembre de 1763 con la mexicana que se viste para encontrar a Rasero, a quien había conocido la noche anterior en un concierto del niño Wolfgang Amadeus Mozart. Recuerda la muerte de su primer esposo, el ya anciano Marqués de las Amarillas, virrey de la Nueva España. Se remonta más en el tiempo, a la época de su niñez, cuando perdió a su familia entera, al momento cuando conoció al Marqués, y al tímido cortejo de éste. Se ve en el día de su boda frente al severo arzobispo de México, Don Manuel Rubio y Salinas. Éste, durante la ceremonia, se transporta a sus tiempos de seminarista cuando, por única ocasión, saboreó el pecado en forma de la angelical prostituta María. En el momento del orgasmo el joven teólogo se vio a sí mismo, mucho mayor y más gordo, frente a un adolescente calvo con ojos brillantes, quien le confiesa sus ya numerosos pecados carnales, durante los cuales tiene visiones raras. Rasero platicará a su Mariana que sólo su primera pareja y un sacerdote, al que no conoce, saben de las visiones. El mismo sacerdote que en el viaje temporal de Mariana, que se viste para ver a Fausto, la casó con el virrey. Partiendo de la boda rememora los pocos días felices al lado del Marqués que culminan en un único encuentro erótico que sirve también como punto final de la vida del Marqués. El siguiente día muere en el jardín Borda de Cuernavaca. Así describe Rebolledo los últimos momentos del virrey:

Mientras se esforzaba por alcanzar la flor, un agudo dolor en la 
cabeza anunció su muerte. Lo comprendió enseguida. No tuvo miedo, curiosamente, su única preocupación era no llegar a alcanzar la flor, 'no llegaré jamás', se dijo, y cayó cuan largo era en el agua tibia que recibió su cuerpo ya desposeído de su alma... Se decidió por el vestido blanco. Después de más de dos años de vestir de luto aún no se acostumbraba a usar ropa colorida. ${ }^{13}$

Casi sin marcar la cesura, el texto regresa a la escena del comienzo. El tiempo de la narración sólo se adelantó un momento, pero este momento abarcó varias existencias, catástrofes, dichas, e inclusive una visión, dentro del pasado del arzobispo, hacia un futuro que para Mariana empieza a ser el presente, es decir: Fausto Rasero.

El caracol barroco y metafísico de Alejo Carpentier se aplica en la novela de Rebolledo como estructura narrativa que reemplaza las palabras cuya función de significar parece ser obsoleta. La narrativa de Carpentier y la de Rebolledo se encuentran en la insistencia de creer en un transcurso temporal barroco, de ninguna manera linear, sino -me atrevo a completar las metáforas biológicas de Carpentier y las químicas de Rebolledo con una de la medicina-a manera de un cáncer que se extiende poco a poco en el cuerpo hacia direcciones no previsibles. Sin embargo, Carpentier analiza tales procedimientos, escribe para lectores guiados por la lógica occidental y por la razón del siglo de las luces. Rebolledo, por otro lado, propone al lector esta estructura temporal como 'eigentliches', ${ }^{14}$ signo que, ahora sí, puede generar y desarrollar su propio contenido.
${ }^{13}$ Francisco Rebolledo, op. cit., p. 298.
${ }^{14}$ 'Eigentlich' es un término en uso en la filosofía alemana. Se podría traducir con 'propiamente dicho', pero implica la suma de significados, cambios de significados, matices y transformaciones que un signo puede sufrir en el transcurso histórico y que apenas lo forman. 